I Universidade Federal do Rio de Janeiro (UFRJ), Rio de Janeiro, RJ, Brasil

michelmisse@gmail.com

Michel Misse'

\title{
IMPRESSÕES DE FOUCAULT: ENTREVISTA COM ROBERTO MACHADO
}

Roberto Cabral de Melo Machado é, desde I985, professor titular, agora aposentado, do Departamento de Filosofia do Instituto de Filosofia e Ciências Sociais (IfCs) da Universidade Federal do Rio de Janeiro (UFRJ), onde ingressou, como professor visitante, em I982. É considerado, no meio acadêmico e fora dele, um dos mais brilhantes intérpretes no Brasil das obras de Michel Foucault e Gilles Deleuze, dos quais traduziu textos, publicou livros e editou coletâneas que marcaram época, a exemplo da então inédita reunião de trabalhos intitulada Microfísica do poder (I979), que alcançou até recentemente 24 edições.

Concluído o curso de filosofia na Universidade Católica de Pernambuco, em I965, Roberto Machado seguiu imediatamente para a Universidade de Louvain, na Bélgica, onde cursou o mestrado em filosofia entre I965 e I969 sob a orientação de Jean Ladrière e defendeu dissertação sobre Husserl. Regressando ao Brasil no ano seguinte, ensinou na Universidade Federal da Paraíba (I970), na Pontifícia Universidade Católica do Rio de Janeiro (I97 I-I98I) e na Universidade do Estado do Rio de Janeiro (I974-I979).

Entre r973 e i98 I fez estágios no Collège de France, sob a orientação de Michel Foucault, e, no ano letivo I985/I986, pós-doutorado na Universidade Paris VIII, com Gilles Deleuze. Em I 978 publicou em livro a pesquisa Danação da norma: medicina social e a constituição da psiquiatria no Brasil, feita em colaboração e já sob o impacto da obra de Foucault. Nela historiciza-se o novo saber da medicina social no Brasil como discurso e prática políticos que atuam na gestão de indivíduos e populações e na normalização da vida social. Em I98I, 
também na Universidade de Louvain, defendeu tese de doutorado sobre a trajetória do método arqueológico de Foucault, publicada no Brasil no ano seguinte como Ciência e saber: a trajetória da arqueologia de Foucault e republicado em 2006 com o título Foucault, a ciência e o saber. Nesse estudo, Roberto Machado analisa tanto o deslocamento operado pela arqueologia em relação à epistemologia - a fim de dar conta de sua especificidade como história dos saberes, que neutraliza a questão da cientificidade - quanto as transformações internas dessa abordagem ao longo do tempo. Assim, sustenta que, com Foucault, a própria ideia de um método histórico imutável, sistemático e universalmente válido perde prestígio. Já em Foucault, a filosofia e a literatura (2000), mostra que o pensador francês valorizou a linguagem literária como contestação e alternativa ao humanismo das ciências do homem e das filosofias modernas.

Além de Foucault, produziu trabalhos reconhecidos e originais sobre Nietzsche, Deleuze e Proust, entre os quais destacamos Zaratustra, tragédia nietzschiana (I 997), Deleuze, a arte e a filosofia (2009) e o estudo, em preparação para publicação, Proust e as artes, sobre as impressões sensíveis, a música e a pintura enquanto condições de possibilidade da concepção proustiana da literatura.

Roberto Machado terminou de escrever seu mais novo livro, que sairá ainda este ano pela N-I Edições, de São Paulo, intitulado Impressões de Michel Foucault, do qual esta entrevista - realizada por e-mail - apresenta uma viva antecipação.

Seguem-se à entrevista três artigos sobre Foucault e sua impressionante atualidade, como se pode comprovar pelos recentes seminários internacionais que tiveram como tema seus primeiros cursos no Collège de France, publicados finalmente entre 2013 e 2015 . O primeiro artigo, de Sérgio Adorno, um dos primeiros sociólogos a estudar e incorporar a obra de Foucault em suas pesquisas no Brasil, oferece um abrangente e rigoroso ensaio sobre os eixos principais que levaram Foucault a se afastar da filosofia convencional, primeiro por meio de pesquisas que o conduziram a uma arqueologia de saberes (história da loucura, o nascimento da clínica, a arqueologia das ciências humanas) que, entretanto, passará por uma profunda inflexão, no final dos anos I960, ao introduzir uma nova abordagem, genealógica, da relação saber/poder e, finalmente, ao pesquisar como modos de subjetivação e modos de produção de verdades encontravam-se diferencialmente fosse no governo de si ou dos outros. O tema da governamentalidade, atualíssimo, e os primeiros esboços de seu pioneiro estudo sobre o neoliberalismo contemporâneo, escritos a poucos anos de sua morte precoce, em I984, aos 58 anos, estão hoje na pauta de vários colóquios, artigos e livros que examinam, em várias partes do mundo, sua pertinência e audaciosa antecipação dos dilemas da racionalidade contemporânea, especialmente após a crise de 2008. O segundo artigo, do sociólogo francês Christian Laval, contempla exatamente a questão do neoliberalismo tal como foi tratada por Foucault e, 
depois, por Bourdieu, e as vicissitudes que se seguiram às suas interpretações no debate contemporâneo. O terceiro artigo, dos sociólogos Bruno Cardoso e Daniel Hirata, propõe-se a defender uma conexão, original e fecunda, entre aspectos da obra de Foucault e da teoria do ator-rede. Estamos agora no campo da experimentação conceitual em pesquisas, nesse caso enfatizando procedimentos de inscrição para pôr em funcionamento programas de gestão de populações e de territórios na cidade do Rio de Janeiro. Mais uma vez, fica patente como os esforços de Michel Foucault para desmontar as totalizações nas ciências humanas, mostrando que a articulação desses saberes com os dispositivos de poder que produzem o governo das populações não se desvincula nem da problemática da soberania na democracia contemporânea, nem dos modos de subjetivação que - da sujeição ao poder disciplinar às formas de autocontrole racional do indivíduo "empreendedor" do mundo neoliberal - marcam os desafios políticos, econômicos e teóricos postos contemporaneamente pelo capitalismo.

Michel Misse. Há autores que ganham notoriedade num certo período e depois desaparecem ou ficam congelados e outros cuja notoriedade e fecundidade se mantêm e até mesmo aumentam com o passar dos anos. Marcuse seria um exemplo do primeiro caso e Foucault, provavelmente, do segundo. Como você interpreta a atualidade de Foucault e seu impacto nas ciências humanas? O que pode ser dito dessa apropriação contemporânea de suas linhas de investigação? Houve de fato uma ruptura importante provocada por sua obra na trajetória do pensamento crítico na filosofia, na história e nas ciências sociais? Essa ruptura se mantém, se aprofunda?

Roberto Machado. Nunca me interessei muito pela questão da notoriedade de Foucault. É verdade que o interesse por sua obra tem crescido desde os anos I960. Há efetivamente uma produção intelectual no âmbito internacional que cada vez mais utiliza suas ideias ou procura compreendê-las de modo mais profundo. Penso em filósofos como Gilles Deleuze, Giorgio Agamben, Toni Negri, Michael Hardt. Ou em sociólogos como Robert Castel e Jacques Donzelot. No Brasil há muita gente pesquisando a partir dele nos campos da educação, por exemplo. E, no mínimo, quatro ou cinco colóquios são organizados sobre ele anualmente entre nós.

Quando penso no que foi a reflexão de Foucault, três principais tipos de estudo despontam, a meu ver, em épocas diferentes de sua trajetória intelectual.

Em primeiro lugar, sua análise histórico-filosófica das ciências do homem na modernidade, quando ele formulou a ideia de que o homem seria uma invenção recente cujo fim talvez estivesse próximo. Mais explicitamente, a ideia de que o homem só apareceu como objeto privilegiado do saber no final do século XVIII e, se as disposições dos saberes modernos viessem a desaparecer, "o homem se desvaneceria como, na beira do mar, um rosto de areia". Seus três grandes livros arqueológicos, da época de I960 - História da loucura, Nascimento 
da clínica e As palauras e as coisas -, ao estudar a psiquiatria, a medicina clínica e as ciências do homem de um modo geral, são no fundo uma crítica do humanismo burguês que procurou ocupar, no mundo moderno, o lugar dos valores antes fundados no absoluto.

Em segundo lugar, a "genealogia", com a qual Foucault procurou explicar o aparecimento desses saberes sobre o homem como elementos de um dispositivo de natureza política. Essa abordagem histórico-filosófica rejeitou a identificação entre poder e Estado, dando importância aos micropoderes; caracterizou o poder não apenas como repressivo, destruidor, mas também como disciplinar, produtivo, normalizador; analisou o saber como peça de um dispositivo político; defendeu as resistências como recusa da dominação burguesa que os próprios saberes sobre o homem ajudaram a criar. Foi a época do estudo sobre a prisão, a escola, o hospital, o hospício, a caserna, em Vigiar e punir, e dos "dispositivos de sexualidade “, entre eles a psicanálise, em A vontade de saber.

Em terceiro lugar, suas pesquisas para dar conta do nascimento do homem de desejo, do aparecimento, na história, do desejo como essência do homem, como se nota modernamente na psicanálise. Isso o levou a recuar ao século V, para dar conta da experiência cristã do sexo. Mas como ainda encontrou uma continuidade temática entre essa época e a modernidade, entre a "carne" medieval e a "sexualidade" dos modernos, recuou ainda mais no tempo em busca de uma descontinuidade fundamental. Foi assim que descobriu que a verdadeira contraposição à moderna hermenêutica do desejo estava na estética do prazer existente na Antiguidade grega e romana. Pois nessa época, em vez de ser objeto de uma ciência sexual, a atividade sexual se constitui como parte do projeto de uma "estética da existência", de uma moral estética, em que se elabora a própria vida como uma obra de arte. $\mathrm{E}$ ao fazer essas análises, $\mathrm{O}$ uso dos prazeres e $O$ cuidado de si se interessam pela constituição de novas subjetividades, pelo contínuo deslocamento da subjetividade na história humana.

Como caracterizar a ruptura que a obra de Foucault produziu, ou melhor, qual é a originalidade, a singularidade de seu pensamento?

Uma das singularidades importantes de Foucault como filósofo é que ele não elabora um método de investigação rígido, invariável, universalmente válido. Sua atitude teórica é marcada - de maneira assumida e refletida - pelo provisório. Em vez de um sistema conceitual, o que há é um processo, ele mesmo histórico, pelo qual seu método é definido de modo diferente em cada obra. Foucault está sempre em constante mutação. É inegável a existência de uma mudança, de uma passagem sem continuidade da arqueologia dos saberes à genealogia dos poderes. E essa mudança é evidente em seu próprio pensamento genealógico, como uma passagem de uma genealogia do poder a uma genealogia da subjetividade. O que começou como uma pesquisa sobre os mecanismos de sujeição converteu-se numa investigação bem diferente - e também original - sobre os modos de subjetivação. 
Na década de I980, poucos anos antes de sua morte, Foucault procurou um diálogo com Habermas. Interessado, na época, pela questão do "esclarecimento", tal como foi pensada a partir de Kant, ele acreditava poder retomá-la de um modo semelhante ao dos trabalhos da Escola de Frankfurt. Por que o diálogo não prosperou? A meu ver, porque Foucault percebeu o quanto o filósofo alemão o tratava como um filósofo tradicional, como criador de um sistema conceitual, criticando seu pensamento passado como se ele existisse em continuidade com o presente, como se sua filosofia formasse um sistema fechado, fosse uma filosofia da identidade.

Outra singularidade de Foucault é a dimensão instrumental de seu pensamento. O importante para ele não era a continuada busca de fundamentação de suas ideias; era o uso delas como instrumento, provisório, parcial, imprevisto, para outros apresentarem suas próprias ideias, criarem seus próprios pensamentos. Por isso, ele fala a respeito delas como "caixas de ferramentas", "bombas", "armas".

O impacto dessas ideias foi grande no Brasil e no resto do mundo, instrumentalizando pesquisas nos campos da filosofia e das ciências humanas e sociais. Depois de sua passagem pelo Rio, em I973, sentindo a importância da concepção do pensamento como instrumento, alguns de nós viram a possibilidade de utilizar seus estudos para a produção de algo novo, que levasse em conta a realidade política e teórica do Brasil. Essa perspectiva foi muito rica, pois efetivamente suas pesquisas estimularam muitas outras sobre a medicina, a psiquiatria, a educação, o serviço social, a prostituição, a prisão, a psicanálise e até mesmo a literatura.

O que motivava minha relação com Foucault era o desejo de fazer alguma coisa a partir de seu pensamento, de usar o instrumental filosófico, ou histórico-filosófico, desenvolvido por ele para produzir um conhecimento novo. Talvez por isso ele tenha apoiado tanto a pesquisa que fiz com três amigos sobre a medicina social e a psiquiatria no Brasil. Ele era marcado por essa dimensão instrumental do conhecimento.

Posso apontar uma terceira singularidade importante de seu pensamento: a atenção à atualidade teórica e política. Uma aguda sensibilidade para as questões da atualidade iluminava suas pesquisas históricas; inversamente, seu constante interesse pelo passado dava uma dimensão mais profunda a sua crítica do presente. Seus estudos sobre os hospitais, os hospícios, as prisões estão ligados a lutas políticas concretas.

Vi certa vez em Paris um filme sobre prisões, e, no debate, fiquei impressionado como a linguagem de ex-presidiários era parecida com a de Vigiar e punir, fazendo-me compreender como as análises históricas de Foucault podiam ser relevantes para a ação política. Por outro lado, essa pesquisa sobre o poder disciplinar deve sempre ser situada num conjunto estratégico, no campo das relações de força que a tornaram possível e que fazem dela uma "história do presente". 
M.M. Você foi dos primeiros, no Brasil, a perceber a importância do que Foucault vinha fazendo e por isso frequentou a partir de 1973 o seminário que ele oferecia no Collège de France e se debruçou sobre sua obra. Você poderia partilhar conosco como se deu esse encontro com Foucault, a partir de quando ele veio para as conferências na PUC do Rio de Janeiro em maio de I973? Ou você já o conhecia antes?

R.M. Cheguei ao Rio de Janeiro, no início dos anos I970, para lecionar na PUC, depois de ter estudado em Louvain, na Bélgica. No Rio, me interessei pela epistemologia francesa, isto é, pela história filosófica das ciências tal como era feita na França por Bachelard, Koyré, Cavaillès, Canguilhem... Mas não estava inteiramente satisfeito. Queria estudar epistemologicamente as ciências humanas e não as ciências da natureza ou da vida, como faziam esses filósofos em relação à matemática, à física, à biologia. Foi quando encontrei As palauras $e$ as coisas, de Foucault.

Folheara o livro quando estudava na Bélgica. Mas, marcado por uma formação fenomenológica e humanística, na ocasião não me interessei por ele. Ao reler As palauras e as coisas, no Rio, minha reação foi bem diferente. Não entendi quase nada desse livro difícil, e, do pouco que entendi, discordei de quase tudo. Mas alguma coisa me levou a pensar que havia ali algo importante, no qual eu jamais havia pensado: a invenção recente - isto é, no início do século XIX - dos saberes empíricos e filosóficos sobre o homem e, além disso, seu desaparecimento, se as configurações modernas dos saberes mudassem. Levei a sério o que era dito, e fiz um esforço desesperado não só para entendê-lo, mas também para compreender por que aquelas ideias eram tão diferentes das minhas.

Por uma feliz coincidência, no ano seguinte, I973, conheci pessoalmente Foucault, que veio ao Rio, convidado pelo Departamento de Letras da PUC, para o pequeno curso de cinco aulas "A verdade e as formas jurídicas". Foi um momento marcante para mim. Essas conferências fazem a genealogia das práticas judiciárias da Grécia antiga, da Idade Média e da Modernidade, apresentando as diferentes formas de relação com a verdade estabelecidas no Ocidente, por meio do que Foucault chamou de prova, inquérito e exame.

Estava nascendo a genealogia do poder, com a qual Foucault explicou o aparecimento dos saberes sobre o homem como peças de relações de poder.

$\mathrm{Na}$ época, mesmo para quem conhecia alguns de seus livros, tudo isso era novo. Essas ideias nunca me haviam ocorrido nem eu jamais havia encontrado em outro pensador. Mas elas me pareceram valiosas sobretudo porque me permitiram pensar filosoficamente as ciências humanas e sociais numa perspectiva teórica e política naqueles anos de ditadura ferrenha.

O mais espantoso, porém, foi que o pensamento de Foucault naquelas conferências era profundamente diferente de tudo o que ele tinha feito - como, por exemplo, em As palauras e as coisas, que eu tinha acabado de descobrir no ano anterior. Fiquei ao mesmo tempo estarrecido e deslumbrado com aquele pensador 
disposto a pensar diferente do que pensara, quando suas pesquisas o levavam a seguir em outra direção, destruindo as evidências estabelecidas e criando novas evidências.

Essa experiência foi tão forte, que, logo depois de conhecê-lo no Rio, e até I98I, aproveitei cinco ou seis férias de verão para seguir seus cursos e seminários no Collège de France. Nos cursos, magistrais, as ideias eram expostas solenemente. Mas Foucault tinha outro lado, igualmente importante. Era homem de passar o dia inteiro pesquisando na Bibliothèque Nationale de Paris. O grande conferencista se harmonizava perfeitamente com o pesquisador de fontes, com uma facilidade extraordinária para encontrar e valorizar documentos esquecidos pelo tempo. E, sobretudo, dar-lhes sentido.

Já os seminários eram descontraídos, com todo mundo falando livremente, expondo as descobertas da semana. Foi aí que ele fez um ótimo trabalho editando as memórias de Pierre Rivière e os autos do processo que ele sofreu, além de publicar notas bastante esclarecedoras sobre o caso, escritas por ele e por participantes do grupo. Cheguei logo depois desse momento, quando membros importantes da pesquisa sobre Rivière ainda continuavam o estudo das relações entre psiquiatria e justiça penal. E aprendi muito ali: a busca incessante dos textos importantes; a preocupação com fatos, acontecimentos, e pouco com teoria; a apresentação cautelosa de uma possível hipótese. Enfim, a cozinha do trabalho de pesquisa.

Depois, a fama começou a perseguir Foucault, fazendo as salas do Collège pequenas demais para os que desejavam ouvi-lo. Além disso, com o sucesso da publicação da pesquisa sobre Pierre Rivière, em 1973, o trabalho em grupo nos seminários começou a tornar-se impossível.

Seus cursos eram bastante diferentes de seus livros. Os cursos eram factuais e históricos, baseados em fontes de primeira mão, sempre em busca das grandes hipóteses capazes de explicar os fatos encontrados. Os livros são organizados a partir dessas hipóteses, e os fatos dos quais elas nasceram aparecem bastante resumidos, ou nem mesmo são mencionados. Para quem quer pesquisar utilizando suas ideias, os cursos de Foucault são até mais importantes do que seus livros, porque nos cursos sente-se mais como ele trabalhava. Os cursos eram provisórios, hipotéticos, empíricos, factuais, sem o arcabouço das grandes teses encontradas nos livros, que eram mais um ponto de chegada, uma conclusão, do que um ponto de partida.

Meu primeiro curso com Foucault foi o de I973-I974 sobre o poder psiquiátrico, uma retomada, de modo bem diferente - genealógico -, da História da loucura, que li na mesma época. E o primeiro seminário de que participei, seguido por filósofos, historiadores, sociólogos, procurava dar continuidade à pesquisa sobre Pierre Rivière fazendo a história da perícia médico-legal em matéria psiquiátrica.

Tocado pela maneira como Foucault trabalhava nos seminários e sobretudo nos cursos, achei que poderia ser eficaz usar aquela "metodologia", aqueles 
procedimentos provisórios, para ligar o discurso filosófico a um conteúdo exterior à filosofia e relacionado ao Brasil, como sua filosofia levava em consideração os saberes extrafilosóficos e a França. Foi então que surgiu a ideia de fazer a pesquisa sobre a medicina social e a psiquiatria no Brasil, que se tornou o livro Danação da norma. Esse trabalho que fiz em grupo, com três amigos, foi importante porque me permitiu pensar filosoficamente numa perspectiva teórica e política, contribuindo para a criticidade e a criatividade que eu procurava alcançar em meu trabalho de professor e pesquisador numa época tão difícil.

M.M. Qual era o clima intelectual no Rio, em pleno regime militar, que favoreceu a recepção dos então chamados "estruturalistas" na psicanálise, no marxismo, nas letras, na filosofia de então (penso aqui, por exemplo, nas edições da Tempo Brasileiro, da Vozes etc.)? Foucault, que era tido, então, como estruturalista, já era bem conhecido em alguns círculos antes de sua vinda ao Rio? As perguntas (ou comentários) que lhe foram dirigidas na mesa-redonda da PUC, publicada pelo Departamento de Letras junto com A verdade e as formas jurídicas, parecem algumas vezes fora de propósito ou deslocadas em relação ao que ele vinha fazendo e expondo, você concorda? O que o seduziu na obra de Foucault, naqueles anos, quando não era comum um filósofo fazer pesquisas como as dele?

R.M. Em I97 I, quando vim para o Rio de Janeiro, um professor universitário passava muito mais despercebido do que numa cidade menor. E ensinar na PUC era bem interessante, porque o clima de liberdade era bem maior do que o das universidades públicas, mais vigiadas e controladas. A PUC do Rio acolhera, aliás, vários professores cassados pelo AI-5, em I 968.

Além disso, havia no Rio, diferentemente das outras cidades do país, grande interesse pelos filósofos da ciência franceses, na PUC e fora dela, entre professores e alunos de filosofia e de ciências da natureza, humanas e sociais. A ponto de, no início dos anos I970, a revista Tempo Brasileiro ter publicado textos deles e estudos sobre eles, comentados por muita gente que encontrei na época de minha chegada. Quando estudava em Louvain, eu não dava importância a esses filósofos, participando do menosprezo, existente na Bélgica e na Alemanha, pela filosofia francesa, considerada repetição enfraquecida de Kant, Hegel, Nietzsche ou Heidegger. Mas a alegria de viver numa cidade onde temas filosóficos abordados por eles a respeito da ciência ultrapassavam os muros da universidade foi determinante para eu orientar meu trabalho de professor na direção que eles propunham.

Estudei a história epistemológica, refletindo filosoficamente sobre temas científicos que eram abordados, com os mesmos alunos, por professores de sociologia, de história, de economia, com quem me reunia periodicamente para planejar o trabalho em comum e avaliar os resultados. Em pleno regime militar, esse trabalho conseguia ser muito proveitoso e prazeroso, porque, ao fazê-lo, senti que podia manter, como professor, uma postura crítica. E isso só se inten- 
sificou quando encontrei Foucault, por causa de sua ideia de que a dimensão política é constitutiva dos saberes e de que é preciso questionar as evidências, os hábitos, os modos de agir estabelecidos, as familiaridades adquiridas. Aprendi com ele que a crítica é um instrumento de luta, de resistência. E para isso, seu curso na PUC, "A verdade e as formas jurídicas", foi muito importante.

Na mesa-redonda que houve na mesma ocasião, numa pequena sala do Departamento de Letras, Foucault procurou esclarecer aspectos de seu pensamento da época, em geral desconhecido ou não muito conhecido dos presentes. Até porque ele fora convidado e era visto no Brasil como estruturalista, e o estruturalismo era muito valorizado no Departamento de Letras da PUC e em vários meios intelectuais do Rio de Janeiro. Acontece que, tendo sido ou não estruturalista, naquele momento ele não era. Ou assim não se considerava, pelo menos desde que terminara As palauras e as coisas ou, mais precisamente, desde I967, quando, numa entrevista - em que aparece, pela primeira vez, a problemática e a terminologia de A arqueologia do saber -, ele se distingue, também pela primeira vez, do estruturalismo, dizendo não se interessar pelas possibilidades formais da língua, que seu objeto "não é a língua, mas o arquivo", o "discurso em sua modalidade de arquivo".

Foi, contudo, uma pergunta sobre a possibilidade do desaparecimento da prática psicanalítica depois de $O$ anti-Édipo, de Deleuze, que deu a tônica da reunião. Pois a resposta de Foucault ensejou a defesa do psicanalista Hélio Pellegrino, desencadeando uma polêmica, e se falou sobretudo de Édipo. Foucault argumentou que Édipo seria um tipo de coação, de relação de poder da sociedade sobre os indivíduos, em vez de uma estrutura fundamental da existência humana, como dizia Hélio. Além disso, esclareceu que não quis falar em suas conferências do mito de Édipo, mas da tragédia de Sófocles, para indicar Édipo-rei como uma dramatização do direito grego, ou, mais precisamente, das práticas judiciárias de busca da verdade no século V antes de Cristo.

Sem dúvida a mesa-redonda da PUC serviu para Foucault apresentar improvisadamente seu pensamento no início de sua genealogia do poder, que ainda não era conhecido. No entanto, a tensão presente na pequena sala, provocada pela disputa intelectual logo instaurada, era insuportável. Encontros como esse logo me fizeram sentir que só se trabalha bem com amigos.

M.M. Como eram as atividades políticas de Foucault no começo dos anos I970? Como ele se relacionava com seus colegas do Collège de France, com os intelectuais da École Normale Superieure ou com a figura então ainda proeminente de Sartre? E com as esquerdas francesas? Como você, então ainda muito jovem, se vê hoje se relacionando, naquele tempo, com a profusão de ideias que - vistas sob a perspectiva de agora - pareciam estar assinalando o apogeu e o fim de uma época, a dos grandes intelectuais públicos, dos grandes debates de ideias e projetos sociais, dos seminários acadêmicos apinhados de gente... 
O que restou de toda essa movimentação intelectual? É possível fazer um esboço de balanço dessa experiência?

R.M. O vínculo de Foucault à política era muito grande e profundo. Ele participou de lutas concretas que ultrapassavam os muros da universidade não apenas pensando a sociedade, mas tomando parte em movimentos visando transformá-la. Era capaz de frequentar a Bibliothèque Nationale durante o dia e à noite participar de uma manifestação. Era um militante intelectual que pretendeu, com seu exemplo, tirar a filosofia do gueto dos especialistas. E, entre suas qualidades, a que eu talvez mais admire é o destemor, a coragem. Era capaz de usar o corpo e a fama, a notoriedade, para denunciar os poderes estabelecidos, suas injustiças e violências, em lutas contra o racismo, a pena de morte, em favor dos imigrantes, dos prisioneiros, dos loucos, dos trabalhadores em greve etc.

Uma das qualidades que eu mais admirava em Foucault era a relação que ele estabelecia entre suas análises histórico-filosóficas e suas ações políticas. Na época em que estava preparando Vigiar e punir, isso se deu pela criação, em I97I, por ele e alguns de seus amigos, do GIP (Grupo de Informações sobre as Prisões). O grupo foi criado e existiu - voltado para lutas políticas locais, parciais, específicas - com o objetivo de chamar a atenção para os problemas das prisões. Mas não se tratava de falar pelos prisioneiros ou de propor reformas. Tratava-se de criar as condições para os próprios detentos denunciarem o que havia de intolerável no sistema de reclusão penal, quanto a alimentação, calefação, salário, punição, cuidados médicos, higiene, direito à informação, visitas íntimas etc.

Apesar de sua importância na contestação do sistema penitenciário francês, o GIP dissolveu-se no final de I972, cedendo vez a organizações de presidiários. Mas Vigiar e punir - em grande parte uma teoria da prisão - foi escrito em íntima relação com essa experiência de dar a palavra aos próprios prisioneiros para que descrevessem os procedimentos de repressão e controle carcerário, contestando as situações em que viviam. É um livro teórico vinculado a uma experiência política.

Influenciado por Althusser, seu professor na École Normale Supérieure, Foucault aderiu ao Partido Comunista, e nele permaneceu de I950 a I953. Mas não parece ter sido um grande militante. Tenho a impressão de que sua sensibilidade política revolucionária se aguçou em I968, e não em Paris, onde ele não estava durante os acontecimentos de maio, mas na Tunísia, onde viveu dois anos como professor e colaborou com um movimento estudantil marcado pelo marxismo, realizando uma série de ações concretas de apoio à greve e à luta.

Uma de suas ações políticas de maior repercussão foi a ida a Madri, em setembro de I975, com intelectuais e artistas, para protestar, com um texto escrito por ele e lido pelo cantor e ator Yves Montand para jornalistas no saguão de um grande hotel. Era um manifesto em defesa de I I militantes políticos condenados pelo regime fascista de Franco ao garrote vil. Denunciava que eles 
não tiveram seus direitos de defesa garantidos e exigia o respeito das regras fundamentais da justiça. Foram violentamente expulsos do país.

Um mês depois, Foucault dava um curso, na USP, sobre a história da sexualidade, quando uma onda de prisões de estudantes, professores e jornalistas foi deflagrada pelos agentes do regime militar na cidade. Foucault compareceu à assembleia universitária que denunciava essas prisões, fez um pronunciamento de solidariedade e anunciou a suspensão do curso. Dois dias depois o jornalista Wladimir Herzog foi morto no DOI-Codi, e Foucault solidarizou-se com as manifestações contra o regime militar que o ato suscitou, como não havia desde I968, dando uma declaração pública de que não ensinava em países onde jornalistas eram torturados e mortos nas prisões. E ainda foi à celebração ecumênica liderada pelo cardeal Paulo Evaristo Arns na Catedral da Sé.

Foucault estava sempre pronto para o combate, disposto a correr riscos. E, como Sartre, com quem ele participou de algumas lutas, sabia muito bem aproveitar o estatuto de intelectual - muito mais claro e respeitado na França do que no Brasil - para intervir politicamente. Essa atitude sempre me impressionou e causou admiração.

M.M. Em I 976 Foucault retorna ao Brasil, faz conferências na Bahia, no Recife e em Belém. A conferência na Bahia foi publicada em Dits et écrits. Como foi isso?

R.M. Suas declarações de repúdio à ditadura brasileira, sua ida ao ato ecumênico tinham o objetivo de provocar os militares, ser expulso do país e chamar a atenção da opinião pública internacional para o que acontecia no Brasil. Mas ele não foi expulso. Então, como soube que sua entrada no Brasil seria proibida, resolveu voltar no ano seguinte, aceitando um convite da Aliança Francesa. Queria forçar o governo brasileiro a negar a permissão para nova viagem ao país, mas também conhecer melhor o Brasil fora do eixo Rio-São Paulo, por causa do elogio que lhe fazíamos de seu potencial revolucionário.

Gostaria apenas de contar um episódio dessa viagem de I976. Quando nos encontramos no Rio antes do início da viagem resolvi adverti-lo da dificuldade que ele poderia encontrar ao falar para os nordestinos. Minha preocupação era que algumas vezes ele havia explicado a tomada de consciência da existência de poderes infinitesimais e múltiplos sobre o corpo - na escola, na família, no hospital, no hospício -, depois da Segunda Guerra Mundial, como uma decorrência da derrocada do fascismo e do comunismo, igualando-os e deles se distanciando em sua análise dos micropoderes. Daí eu lhe dizer: "O público universitário nordestino é diferente do carioca ou paulistano: é muito mais marxista. Tenha cuidado com o que vai dizer. No Sudeste se respira um ar bem parisiense de crítica do marxismo e do comunismo. Mas, no Nordeste, quem é engajado politicamente de maneira revolucionária em geral é marxista ou próximo do marxismo. É preciso respeitar isso!" E sua resposta me como- 
veu: "Jamais falaria contra o Partido Comunista quando ele é proscrito e seus membros estão na cadeia".

Fato é que, já em Salvador, na primeira conferência na Faculdade de Filosofia e Ciências Humanas da Ufba, Foucault mostra que ouviu o conselho. A tradução dessa conferência foi publicada pela revista anarquista Barbárie, no início dos anos I980, com o título "As malhas do poder" e depois no Dits et écrits. E quando se lê o que disse Foucault, nota-se que, embora critique o "marxismo acadêmico" por uma concepção jurídica do poder e por privilegiar o aparelho de Estado, ele defende sua própria concepção tecnológica do poder a partir de O capital. Assim, apresenta como sendo de Marx hipóteses levantadas em seus últimos escritos: não existe um, mas vários poderes, regionais, heterogêneos, específicos; eles não são a consequência de um poder central, mas, ao contrário, lhe são anteriores; esses poderes não têm a função primordial de proibir, mas de produzir; eles se caracterizam por tecnologias de controle dos indivíduos e das populações: a anatomopolítica e a biopolítica, a disciplina e a regulação.

Não há dúvida de que a obra de Foucault é atravessada por um diálogo com Marx. Isso é nítido - como talvez em nenhum outro momento - no curso do Collège de France de I972-I973, A sociedade punitiva, e em Vigiar e punir. Também é inegável que Marx se refere, em O capital, ao controle, à vigilância, à disciplina em vigor no ateliê e na fábrica, e que Foucault conhecia essas análises. Mas, como ele estava apresentando em Salvador ideias gerais sobre os micropoderes, decorrentes de suas próprias pesquisas, expostas em Vigiar e punir e em A vontade de saber, a presença estratégica de Marx nessa palestra não é importante em sua argumentação. Isso pode ser notado, aliás, quando, depois de afirmar que "Marx faz análises magníficas do problema da disciplina no exército e nas fábricas", ele emenda dizendo que sua análise da disciplina no exército "não se encontra em Marx, mas pouco importa". E ainda pode ser notado quando, algumas vezes durante a palestra, ele torna sua análise mais sutil ao dizer que isso está "implícito" em Marx e nas entrelinhas de O capital.

A meu ver, histórias como essa realçam o lado estratégico do comportamento de Foucault, bem como a ideia de que não se deve aprisionar o que ele disse num sistema. 
Michel Misse é professor titular do Departamento de Sociologia do Instituto de Filosofia e Ciências Sociais da UFRJ, pesquisador I-B do CNPq, coordenador do Núcleo de Estudos da Cidadania, Conflito e Violência Urbana (Necvu/UFRJ), vice-coordenador do Inct "Violência e segurança pública" e autor, entre outros livros, de Crime e violência no Brasil contemporâneo (2006). É também editor de Dilemas - Revista de Estudos de Conflito e Controle Social. 


\section{IMPRESSÕES DE FOUCAULT: ENTREVISTA COM ROBERTO MACHADO}

\begin{abstract}
Resumo
Nesta entrevista sobre Michel Foucault, Roberto Machado aborda sua atualidade e seu impacto nas ciências humanas; os tipos de estudo que caracterizam diferentes momentos de sua trajetória intelectual; as singularidades de seu pensamento - o método provisório, a dimensão instrumental do conhecimento e a atenção à atualidade teórica e política -; bem como o vínculo entre suas análises histórico-filosóficas e suas ações políticas. Relata a vinda de Foucault ao Brasil durante a ditadura militar, o encontro com o pensador francês e sua obra, a experiência em seus cursos e seminários no Collège de France. Comenta ainda o aprendizado da dimensão política dos saberes como um instrumento de luta e resistência.
\end{abstract}

\section{IMPRESSIONS OF FOUCAULT: AN INTERVIEW WITH ROBERTO MACHADO}

Abstract

In this interview on Michel Foucault, Roberto Machado discusses his contemporary relevance and his impact on the human sciences; the types of study composing the different periods of his intellectual trajectory; the singular aspects of his thought - the provisional method, the instrumental dimension of knowledge and the attention to the theoretical and political present; as well as the link between his historical-philosophical analyses and his political actions. He recalls Foucault's visit to Brazil during the military dictatorship, the encounter with the French thinker and his work, and the experience of his courses and seminars at the Collège de France. He also comments on learning about the political dimension of knowledge as a tool for struggle and resistance.
Palavras-chave

Michel Foucault;

Roberto Machado; saber e poder; ação política; crítica do presente.

Keywords

Michel Foucault; Roberto Machado; knowledge and power; political action; critique of the present. 